https://doi.org/10.22364/hssl.27.2.02

\title{
TRENDS IN THE USE OF INFORMATION CHANNELS FOR PERSONNEL RECRUITMENT IN MEDIUM AND SMALL ENTERPRISES
}

\author{
Ilze Boitmane \\ Mg. HRM \\ Inesa Vorončuka
}

Dr. oec.

\begin{abstract}
Information channels are the main tool for attracting human resources to an organisation. Over time, these channels change depending on the behaviour of job seekers and technological developments. Nowadays, types and channels of searching for a job are different both from the point of view of the employer and the job seeker. Businesses are struggling to find and address potential candidates, as is testified by the high number of open vacancies and employee recruitment activities. The novelty of the article is characterised by the rapid development of digital environment in business, including personnel recruitment, and there is a need to develop new approaches and strategies for companies to find the necessary employees more efficiently and quickly. The goal of the article is to identify and illustrate habits of use of informative channels in medium and small enterprises in Latvia. The theoretical framework is based on world-wide research on peculiarities of use of information and communication channels in the context of personnel recruitment. The diversity of channel terminology and theoretical aspects are discussed from the point of view of digital technology development, external human resource management marketing and social media. The methods used in the research are analysis of theory and statistics, and an empirical research on the use of information channels in medium and small enterprises in Latvia. The authors of the article conducted a study on 80 medium and small enterprises of an improbable sample and established that, in Latvia, the most frequently used tools of personnel recruitment are corporate websites, internship programs, LinkedIn, Facebook. The results using the continuous rating scale indicate that enterprises are relatively little focused on intensive attraction and search for employees, which testifies that there is a lack of corporate strategy and unified policy in the context of attracting employees. The results obtained do not fully support the fact that digital recruitment resources dominate, as is the case in the theoretical research. The authors of the article conclude that digitalisation is slowly increasing in the field of recruitment, enterprises choose the most affordable and accessible information channels that require insignificant digital skills of employees, and observe a rapid development of internship vacancies and programs, and increased use of such digital channels as social media. Enterprises need to organise their recruitment activities in a planned and strategic
\end{abstract}


way, selecting the most effective channels, and to increase the use of personnel recruitment and selection tools.

Keywords: Latvia, Human Resources Management, Personnel Recruitment, Personnel Selection, Information Channels, Communication Channels

\section{Introduction}

During the last decade, medium and small businesses have been struggling in finding employees and have insufficient resources and competences to address and attract potential candidates. Scientists emphasise that, currently, there is shortage of human resources, and unique and new tools are necessary for organisations to attract new employees successfully, Friedman (2006).

The goal of the article is to identify and illustrate the habits of use of informative channels in medium and small enterprises in Latvia. The tasks include: to explore the link between information and communication terminology and the personnel selection, to illustrate theoretical aspects, to reflect the data from the practical research and their compliance or nonconformity with the theoretical framework. As a result, to reflect the main conclusions, discoveries, and to suggest proposals for further development of the topic.

In the article, the authors study theoretically the information channels for personnel attraction from the following aspects: information and communication channel aspect, external aspect of human resource management marketing, information technology and digitization aspect, social media aspect, including practical research of information and communication channels in medium and small enterprises.

The novelty of the article is characterised by the rapid development of the digital environment in business, including personnel recruitment, and there is a need to develop new approaches and strategies for companies to find the necessary employees more efficiently using the digital tools such as information channels. Novelty is the dominant position of digital information channels in personnel recruitment, which are replacing the traditional channels and create new interconnections that stimulate discussions of further research.

The problem question of the research: how do the habits of using information channels develop in medium and small enterprises and how can they solve the problems of attracting personnel? Enterprises have difficulties in attracting employees, and there is no consistent answer to the question - is there a lack of employees as such, or is it just the inability of certain companies to attract talent? To what extent will the information and communication channels become 'robotised' or 
remain 'human'? The authors of the article reveal a versatile research of the use of informative channels in practice and in theory.

Research shows that companies require a new strategy to be able to use digital channels in human resource management in a structured manner to attract new employees. Regarding the search for employment, the emphasis is placed on peculiarities of thinking of the generations $X$ and $\mathrm{Y}$, as most of them have grown up in close connection with the media environment, the internet and virtual exchange of information, and social communication channels. Therefore, the pre-existing methods and approaches for informing, addressing and communicating with this generation from the point of view of human resources are no longer effective and are unable to reach the target audience, Prensky (2001). Researchers highlight a number of digital media that are effective in attracting employees such as Facebook, Twitter, LinkedIn, Google+, etc., which are effective in the world. The authors note the importance of not only using specific channels or media, but the strategy and approach of how these channels are used, Friedman (2006).

\section{Theoretical Frame of the Article}

\section{The dilemmas in the formulation of the term "channels"}

Information channels are the basic tool for searching and attracting new employees to an organisation. Only information channels are the way job seekers and the public learn about a company's current vacancies. 'Information channels are various ways of communicating information to existing and potential customers. Distribution channels include mail, press attachments, phone, electronic and mass media, global distribution systems, etc. Diverse use of distribution channels expands the range of customers by offering them an assortment of services and goods, as well as the terms of purchasing. See also Global distribution system', Academic Database of Terminology (2005). In the world, information channels are often referred to as communication channels used to communicate, for example, with customers, employees, potential candidates, Cambridge Academic Content Dictionary (2019). When discussing the terms from the personnel recruitment and attraction aspects, there is a difference, because information channels are the place where a job seeker finds information, and communication channels are the way how the job seeker looks for and makes contact with the potential employer. Based on different terminology, both terms are equally important, therefore communication channels are included in further research of information channels. The third term in the context of the article is external marketing of human resources management. In 
German, the term is 'Personal Marketing, Personalmarketing, Personnel marketing', which translates directly as Personnel Marketing, Frahling (2015). Human resources marketing is defined as the traditional marketing, transforming the marketing ideas as marketing concepts in the context of human resources management, Beyer (1990). Personnel marketing essentially is product or sales marketing, which is used in the context of personnel management, Bieberstein (2006).

Subsequently, the authors of the article emphasise that it is equally important to use the terms information, communication channels and marketing of external human resources when it comes to information channels in a more global context of human resource management. The authors note that in different foreign languages these terms are used in a different context if they are not viewed as a single whole.

\section{The rapid development of digitalization in human resource management}

\section{E-HRM, E-Recruitment}

Over time, information channels change depending on the behaviour of job seekers, their geographic location, age and technological development; as well as employers' information and communication with job seekers have changed both from the aspect of changing habits of job seekers, and changing habits of enterprises and business development trends. Researchers note that, as generations change, digital tools play an increasingly important role both from employers' and job seekers' point of view.

The use of digital technologies in recruitment not only provides a wide availability of resources, but similarly important is their ability to perform activities in a short time, reducing the time required for personnel selection. Career information pages, vacancy portals, outsourcing agency websites, various media web pages, interactive websites or on-line research platforms, E-college or educational websites, CV publishing in digital environment, blogs, selection through social networks, targeted job search in the digital environment like Job Dating and Speed Dating are named as effective information channels for personnel attraction and recruitment, Florea, Badea (2013).

Recently, E-Recruitment has become popular, a new approach to searching for employees, which also largely underpins the social media approach. It is a tool and a way of retrieving and processing information in digital environment that provides employee searching functionality, and this direction will develop rapidly in the future, Kiselicki, Josimovski, Kiselicka, Yovevski (2018). In the E-Recruitment environment, it is possible to create special tools that ensure fast and efficient exchange of information between job seekers and employers. In general, this technology is based 
on Web Technologies of Semantic Networks. This technology will improve the exchange of information and communication between the employer and the job seeker in the future, Enăchescu (2016).

'The findings offer support for the view that the website's content, jobseeker knowledge of the organisation, and the job-seeker's social network influence positively perceptions of fit to the organisation and the job in meaningful ways', Eveleth, Stone, Baker-Eveleth (2018).

The development of E-HRM and E-Recruitment is an important feature for the ability of enterprises to recruit efficiently in the future. Social media and social network platforms and their use play an important role in this respect, Ramkumar (2018). A more advanced resource approach is reflected in a study on the effectiveness of using VVC (Virtual Call Center) recruitment agents in personnel recruitment. It reflects that the main emphasis is placed on the digital environment as a channel for recruitment. The authors of the research found that the use of VCC marks a high efficiency in personnel selection, Yakubovich, Lup (2006). Research shows that the internet is the most effective channel for searching for personnel, Khan, Awang, Ghouri (2013).

\section{External Human Resource Management Marketing is an information and communication channel for personnel recruitment}

Personnel selection and recruitment channels are also defined as external human resources management marketing, which includes such important information and communication channels for communication with job seekers as digital and media platforms, social media, participation in public and career exhibitions, career days, new talent programs, internship programs, and companies' publications in the media, Moser (2012).

The German authors, when studying the brand identity of the employer, created a separate term 'marketing of personnel' and a structure in which the marketing of personnel consists of the following elements: internal and external personnel marketing and personnel management research. As external personnel marketing, a marketing plan with the aim of attracting new employees the company is meant, Haubrock, ÖhlschlegerHaubrock (2009).

Human resources marketing is a skill to 'sell a part of personnel', and actually it means a capability to create powerful and effective tools and methods that would help human resources managers to attract new employees to their organisations. Any organisation's strategy must have a personnel marketing policy for the implementation of the external marketing strategy that the author emphasises in his research, Rose (2007). One of the human resources marketing actualities and tasks in the coming years is the necessity to attract new talents. It will command 
employers to use marketing - in order to promote the recognition of the employer's image and to advance the public relations of talent or the 'talent hunt', Fahrbach (2013).

Human resources marketing is an essential tool of external marketing communication, and with its help, it is possible to promote the human resources of an organisation, attract new employees, in other words, to use it as a human resources selection tool, Hunziker (1973). Personnel marketing is a tool with high added value in business that is focused on both internal communication with employees and external with customers, Eckardstein, Schnellinger, Schmitdbauer (1975). Human resources marketing is not only an advertising tool, but a body of functions that can externally motivate the current employees of an organisation, attract and motivate potential new human resources and be an extremely effective tool for organising human resources selection and attraction, Frölich (1987). In 1987, researchers included the personnel marketing term as a cultural element of a unified organisation, Meyer (1987). The further development of human resources marketing is marked by another new tendency - the development of technology and widespread use of the internet in everyday communication. Thus, the new communication style on the internet is identified by the terms: social networks and social media. From the aspect of human resource marketing, they acquire a new significance - employees can use the social media: as a communication tool, to reflect their experience by sharing it, and to perform remote job functions, Meckel, Schmid (2008).

Personnel selection and recruitment marketing, emphasizing the practical aspects of its management, covers not only the strategic importance of personnel marketing, but also reveals a detailed plan and structure. For successful organisation of the process, the following plan is needed, as well as the role of information and communication channels, such as establishment of an external and internal social network before the commencement of the selection project and establishment of a system of attracting internal and external new talents, as well as selectively actively promoting the latest vacancies using available resources and media, Syedain (2013).

\section{The role of social media and channels in attracting labour market potential}

In recent years, the role of social media in the context of personnel marketing increases. Many authors emphasise that daily communication of human resources of an organisation is not possible without social networks where employees exchange knowledge and experience. This is 
noted by researchers in their research already in 1998, discussing social networks as trends of modern society and the main channels for obtaining and exchanging information, Nahapiet, Ghoshal (1998).

Social media are one of the main sources of information in personnel selection, for instance, for direct attraction of candidates, communication with potential candidates, publishing of job advertisements, as well as examination of candidates' profiles. A marketing strategy is necessary on how to use these media for selection and recruitment, Headworth (2015).

A research performed by Jobvite confirms that the most popular information channels for employee recruitment are social media, especially LinkedIn, Facebook, Jobvite Ltd. (2014).

Australian researchers and research organisations through extensive research studied various aspects of human resource management, including information channels, such as media and communication channels, and concluded that the most widely used channels were social media, career and vacancies' websites. Part of the research was related to the selection of personnel, where companies involved in the study indicated that advertising directly in the field of recruitment advertising and human marketing development was the key to how they saw the development of their brand, Minchington (2010).

The approach of the Society for Human Resource Management (SHRM) reflects traditional personnel recruitment channels and resources such as employee referrals, newspaper ads, recruiting firms, college recruitment, contingent firms, job fairs, the internet, targeted minority recruiting, government employment services.

To identify the potential of the employment market, information channels and resources such as the corporate website, recruitment agencies, employee referral schemes, professional networking, commercial job boards, local newspaper advertisements, specialist journals, Jobcenter, search consultants, links with educational establishments, national newspaper advertisements, social network sites can be used, Armstrong, Taylor (2014).

\section{Results and Discussion of the Research}

The research conducted by the authors of the article was based on the criteria and constructs put forward by the research by Minchington and Moser, which have been used in surveys of the research, and the main aspects of the practical study are visually reflected in Figure 1 by the authors of the article, after which the item set 'Analysis of Information Channels in Personnel Attraction and Selection' of the research 'Development of Personnel Marketing in Latvia', conducted in 2016, was analysed. 


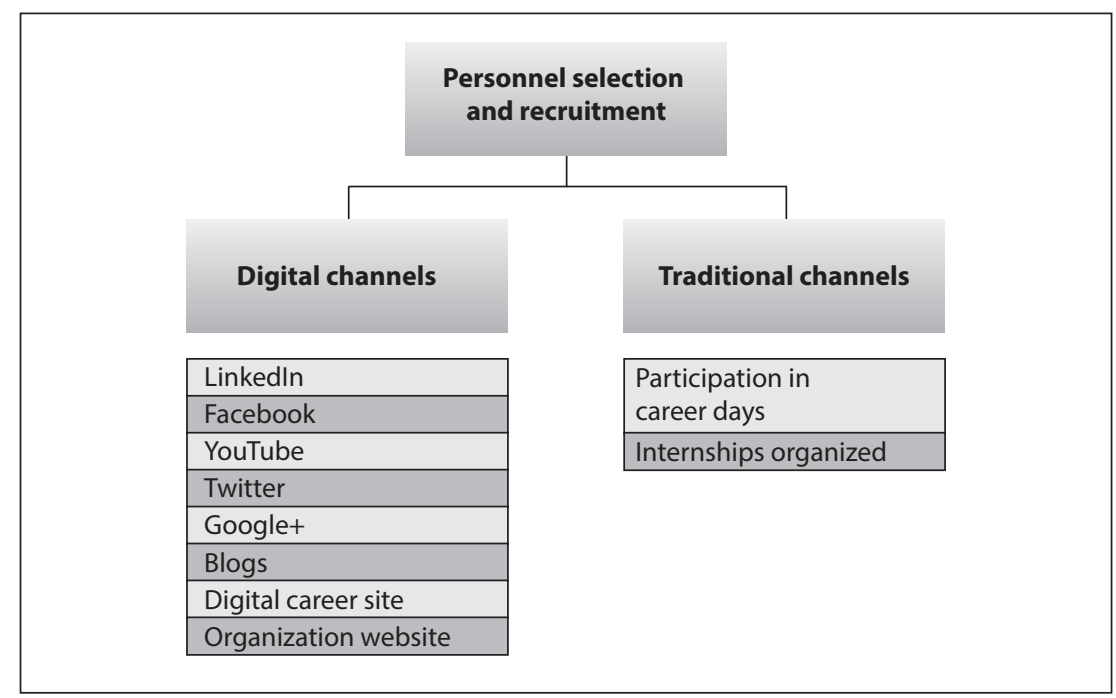

Source: Criteria for Personnel Selection and Recruitment Research Based on Moser, Minchington

Figure 1. Distribution of personnel selection and recruitment resources, created by the authors

\section{Methods of the research}

The research is based on study and analysis of theory and research in the world. The empirical research is based on a survey conducted in 2016. The data collection method is analysis of the set of items 'Use of Information Channels in Recruiting New Employees' from the survey conducted in 2016, 'The Study of Human Resources Management Marketing', using the analysis of the Central trend indicators.

The research limitations are related to the fact that the data obtained in the study are not fully representative because the research was performed on improbable sample. Thus, the results obtained can only partially reflect the results and partly complement the findings.

The study sample consists of 80 medium and small enterprises in Latvia, with the set of 449 respondents. The study selection criteria: the organization has a website; the organization publishes job offers; the organization has personnel management functions and external activities, which was identified using the data of the Central Statistical Bureau of Latvia, Lursoft and Eurostat on 2016 topical information. Based on these criteria on a random basis, a probable sample should be 218 respondents with a limiting error 5\%, Boitmane (2016). 


\section{Results of the research}

The authors of the article have inspected the topic from the theoretical aspects, performed the analysis of secondary data or statistics, as well as analysed the empirical research performed on improbable sample. In general, the results of the study are related to theory and research.

In Figure 2, the data obtained in the survey are shown, where information channels for personnel selection and recruitment in small and medium-sized enterprises have been elicited.

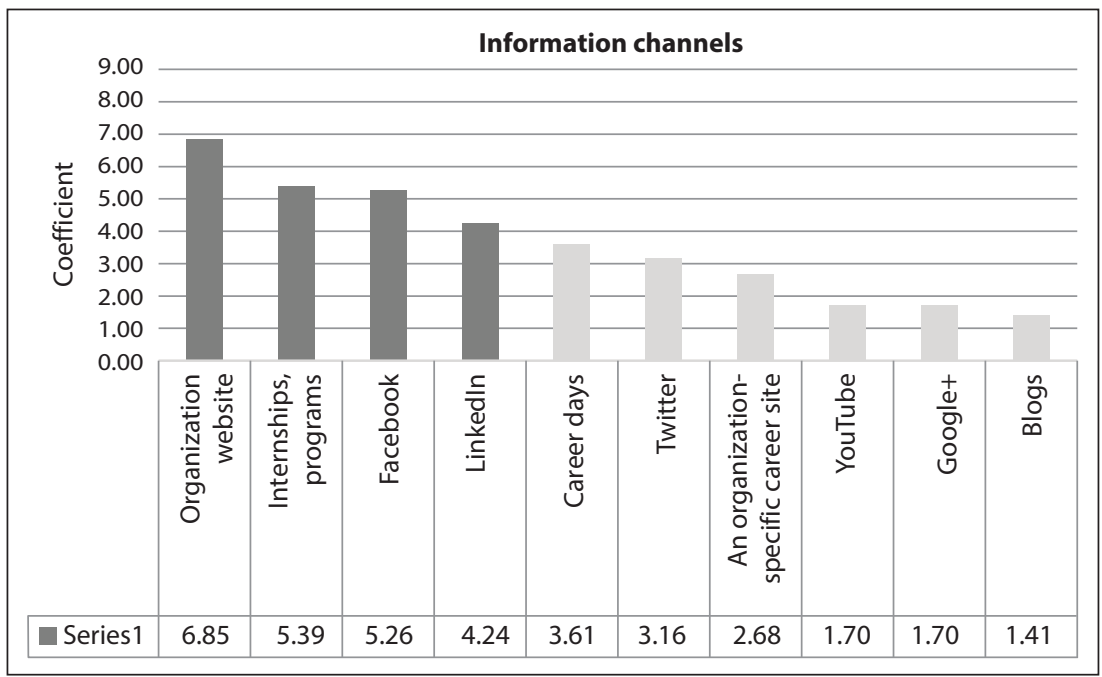

Figure 2. Information channels for recruitment and selection at medium and small businesses.

In Figure 2, the usage patterns of information and communication channels in small and medium enterprises in Latvia are reflected. This shows that companies extensively use their corporate websites as a resource to search for employees. There is a high proportion of using social networks, e. g. LinkedIn and Facebook, as well as a high result for the traditional way of attracting employees by organising internships in companies, thus attracting new talents. The results show that the use of digital information channels have gained a higher proportion, which corresponds to the theoretical aspects of the article. However, under discussion is the fact that, alongside the digital media, which is the internet and social media, there are traditional approaches based on direct physical contact with the participants of the employment market. This calls for a new research question that the digital environment will not be able to 
fully replace the physical contact needed by the employer to establish contact with a potential job seeker. The results shown in the figure testify that companies generally do not make full use of information channels and resources for personnel selection and recruitment, since the arithmetic mean of the possible rating 9 is 3.6, the maximum value is 6.85 , indicating a low score. Indicators of the Central trend show that the mean is 3.6, which can be seen from the indicators of the Descriptive Statistics, Table 1.

Table 1. Descriptive Statistics 'Information channels for recruitment and selection at medium and small businesses.

\begin{tabular}{|c|c|c|c|c|c|c|}
\hline & $\mathrm{N}$ & Minimum & Maximum & Sum & Mean & Std. Deviation \\
\hline $\begin{array}{c}\text { Information } \\
\text { channels } \\
\begin{array}{c}\text { Valid N } \\
\text { (listwise) }\end{array}\end{array}$ & 10 & 1.41 & 6.85 & 36.00 & 3.6000 & 1.82538 \\
\hline
\end{tabular}

In accordance with the practical research, the authors looked at the available statistical data, which reveal more about the phenomenon of the research. Figure 3 reflects the data from Eurostat.

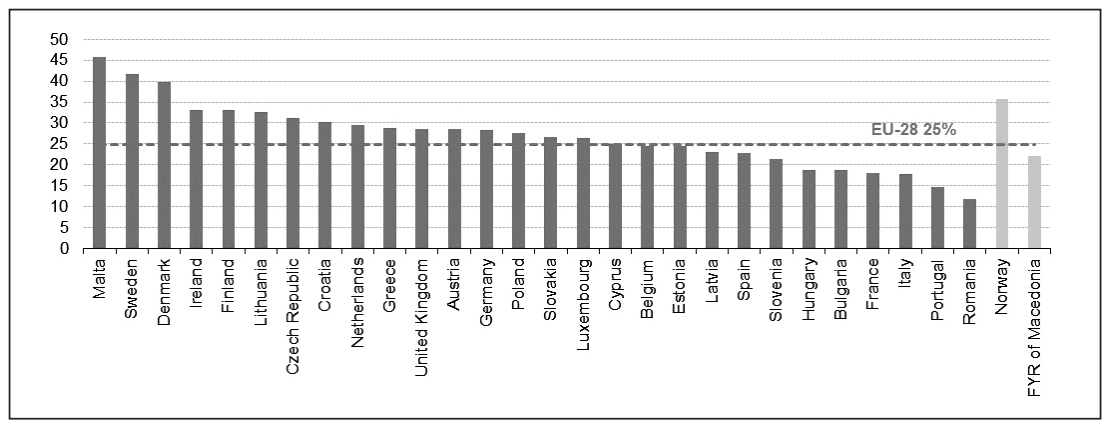

Source: Eurostat Research Dates, 2016

Figure 3. Enterprises advertising on the internet, 2016 (\% of enterprises) Eurostat (2016)

Figure 3 shows the research data from 2016 Eurostat study on the companies' use of the internet, which is also related to the topic of the article. Research data show that in Latvia the percentage of internet usage is $24 \%$, while in Malta $45 \%$ of companies use the internet for advertising purposes, meanwhile the lowest rate is in Romania, where only $13 \%$ of companies use the internet. Overall, it outlines that medium and small enterprises in Latvia use the internet environment for advertising purposes 
relatively little, it is also closely related to advertising in the context of human resources and recruitment, Eurostat (2016a). Another Eurostat study more precisely outlines the use of the internet among medium and small businesses, as opposed to large companies, where the capacity of medium and small businesses in various forms of on-line advertising activity is at least $20 \%$ lower than for large companies, Eurostat (2016b). The above-mentioned data confirm the correlation between the results of the empirical research, that in Latvia medium and small enterprises use the internet in insufficient amount and capacity.

\section{Conclusions and Proposals}

According to the theoretical framework and the data obtained in the research, the authors conclude that small and medium enterprises use information channels insufficiently to attract and select personnel. Businesses choose the information channels that are the cheapest, most affordable, and require insignificant digital competencies. Medium and small businesses mainly use digital resources rather than traditional resources for information placement and advertising to attract the workforce, and corporate website, and great emphasis is put on using social media for personnel selection and recruitment. This can be substantiated by the low costs of these resources and relatively simple technical solution that does not require users to have a high level of digital competence. The results of the research show that the implementation of internship programs is very popular in order for medium and small companies to attract new employees and talents, which was a discovery for the authors during the research. This result was not anticipated and may trigger further research.

The limitation of the article's author's research is that the obtained data are not representative, therefore a study on a representative sample is needed to unambiguously interpret the results of the study.

The authors of the article encourage discussions and suggest that companies need to organise the recruitment measures in a planned and strategic way, creating a strategy, a marketing plan that would allow more extensive use of informative resources in attracting employees. In order to use digital media, it is necessary to increase the digital competencies of the human resources departments, as the available statistical data and research data indicate that there is a low use of digital technologies. In addition, medium and small enterprises need innovations and faster deployment of new technologies in human resource management, including personnel selection.

The findings of the research about the development of internship programs encourage discussion that these results have not been predicted and require an in-depth study of this phenomenon on the development 
Humanities and Social Sciences: Latvia (Volume 27(2))

of internships in companies and subsequent succession. In addition, the research should include a study of job search channels for $\mathrm{X}, \mathrm{Y}$ and $\mathrm{Z}$ generations of job seekers.

\section{REFERENCES}

Armstrong, M., Taylor, S. (2014), Armstrongs Handbook of Human Resource Management Practice. $13^{\text {th }}$ Edition. UK: Oxford Color Press Ltd. Pages 842. p. 228-233.

Beyer, H. T. (1990), Personallexikon. Germany: München, P. 392.

Bieberstein, I. (2006), Diensleistungsmarketing. 4. Überarbeitete und aktualisierte Auflage. Germany: Ludwigshafen am Rhein, P. 83.

Boitmane, I. (2016), The Development of Human Resources Marketing in Latvia. Master Thesis. Riga: RISEBA, pp. 99.

Cambridge University (2019), Cambridge Advanced Learner's Dictionary \& Thesaurus and from the Cambridge Academic Content Dictionary. [Online] Available at: https:// dictionary.cambridge.org/pronunciation/english/channel-of-communication [Accessed 30.03.2019].

Eckardstein, D., Schnellinger, F. (1975), Personalmarketing im Einzelhandel. Eine Fallstudie. Deutschland: Berlin. Dunker \& Humbolt. P. 85.

Enăchescu, M. I. (2016), A Prototipe for an E-Recruitment Platform using Semantic Web Technologies. Journal: Informatica Economică, Vol. 20, no. 4/2016

Eurostat (2016), Enterprises advertising on the internet. [Online] Available at: https:// ec.europa.eu/eurostat/statistics-explained/index.php?title=File:Use_of internet ads_by_type_and_by_enterprise_size,_EU-28,_2016_(\%25_enterprises_advertising_ on_the_internet).png [Accessed 01.04.2019]

Eurostat (2016), Use of internet ads by type and by enterprise size, EU-28, 2016 (\% enterprises advertising on the internet. [Online] Available at: https://ec.europa.eu/eurostat/statisticsexplained/index.php?title=File:Enterprises_advertising_on_the_internet,_2016 (\%25_enterprises).png [Accessed 01.04.2019].

Eveleth, D., Stone, R., Baker-Eveleth, L. (2018), The influence of recruitment websites on job-seeker perceptions of organization and job fit. International Journal of Technology and Human Interaction. Volume 14, Issue 4, p. 1-22.

Fahrbach, S. (2014), Personalmarketing. Anspruch und Wirklichkeit. Germany. Druck und Bindung: Books on Demand GmbH. P. 24.

Florea, N.V., Badea, M. (2013), Acceptance of new Technologies in HR: E-Recruitment in Organizations. Proceedings of the European Conference on Information Management $\mathcal{E}$ Evaluation, 2013 Year, Volume 5, Issues 13, p. 344-352

Frahling, G. (2015), Linguee Wörterbuch. [Online] Available at: http://www.linguee.de/ deutsch-englisch/uebersetzung/Personalmarketing.html [Acceseed 09.10.2015].

Friedman, B. (2006), Marketing in Times of Scarce Human Resources. The CPA Journal. USA: New York.

Frölich, W. (1987), Strategisches Personalmarketing. Deutschland: Düsseldorf.

Haubrock, A., Öhlschlegel-Haubrock, S. (2009), Personalmanagement. 2. vollständing überarbeitete Auflage. Deutschland: Stuttgart. P. 258. 
Headworth, A. (2015), Social Media Recruitment. How to successfully integrate social media into recruitment strategy. USA: Kogan Page. P. 220.

Hunziker, P. (1973), Personalmarketing. Deutschland: Haupt Verlag.

Jobvite Ltd. (2014), Social Recruitment Survey 2014. [Online] Available at: https://www. jobvite.com/wp-content/uploads/2014/10/Jobvite_SocialRecruiting_Survey2014. pdf [Accessed 1.10.2015].

Khan, R., Awang, M., Ghouri, A. M. (2013), Impact of E-Recruitment and Job-Seekers Perception on Intention to Purue the Jobs. Journal: Management $\mathcal{E}$ Marketing, Volume XI, Issue 1/2013.

Kiselicki, M., Josimovski, S., Kiselicka, M., Jovevski, D. (2018), Analysis of E-recruitment Methods through SNWS, with special Emphasis on the Republic of Macedonia. Journal of Sustainable Development (1857-8519), Dec 2018, Vol. 8, Issues 21, p. 19-34, 16. $\mathrm{p}$

LZA (2005), Akadēmisko terminu datu bāze. [Online] Available at: http://termini.lza.lv/term. php?term = inform $\%$ C4\%81 cijas $\% 20 \mathrm{kan} \%$ C4\%81ls\&list=D $\% 20 \mathrm{kan} \% \mathrm{C} 4 \% 81 \mathrm{ls} \& \mathrm{lang}=\mathrm{LV}$ [Accessed 28.03.2019].

Meckel, M., Schmid, B. (2008), Unternehmenskommunikation. Kommunikationsmanagement aus Sicht der Unternehmensführung. 2. Auflage. Germany: Wiesbaden. P. 556.

Meyer, W. (1988), Personalmarketing. Deutschland: München.

Minchingthon, B. (2010), 76\% of Companies Choose Social Media to Communicate Employer Brand. Employer Brand International Magazine. 1 May 2015. [Online] Available at: http://www.careerarc.com/blog/2014/06/76-companies-choose-socialmedia-communicate-employer-brand/ [Accessed 20.11.2015].

Moser, B. (2012), Personal marketing. [Online] Available at: http://www.hrundleadership. ch/human-resources/personalmarketing/ [Accessed 10.10.2015].

Nahapiet, J., Ghoshal, S. (1998), Social capital, intellectual capital and the organisational advantage. Academy of Management: Academy of Management Review. Vol. 23, No. 2 (Apr., 1998), pp. 242-266.

Prensky, M. (2001), Digital Natives, Digital Immigrants Part 1. On the Horizon. Vol. 9, Issue: 5 , pp.1-6.

Ramkumar, A. (2018), E-recruitment through job portals and social media network: Challenges \& opportunities. Indian Journal of Public Health Research and Development, Volume 9, Issue 6, June 2018, pp. 143-148.

Rose, M. (2007), What can HR learn from marketing? [Online] Available at: http://www. employeebenefits.co.uk/home/current-issue/what-can-hr-learn-from-marketing/3141. article [Accessed 01.10.2015].

Syedain, H. (2013), The new rules of Recruitment. Journal: People Management. 1 July 2013.

Yakubovich, V., Lup, D. (2006), Stages of the Recruitment Process and the Referrer's Performance Effect. Journal: Organization Science, Vol. 17, No. 6, NovemberDecember 2006, pp. 710-723. 